\title{
Approved Glycopeptide Antibacterial Drugs: Mechanism of Action and Resistance
}

\author{
Daina Zeng, ${ }_{1}^{1}$ Dmitri Debabov, ${ }^{2}$ Theresa L. Hartsell, ${ }^{3}$ Raul J. Cano, ${ }^{4,5}$ Stacy Adams, ${ }^{6}$ \\ Jessica A. Schuyler, ${ }^{4}$ Ronald McMillan, ${ }^{4}$ and John L. Pace ${ }^{4,7,8}$ \\ ${ }^{1}$ Agile Sciences, Raleigh, North Carolina 27606 \\ ${ }^{2}$ Emery Pharma Services, Emeryville, California 94608 \\ ${ }^{3}$ Department of Anesthesiology/Critical Care Medicine, The Johns Hopkins School of Medicine \\ and Nursing, Baltimore, Maryland 21287 \\ ${ }^{4}$ ATCC Center for Translational Microbiology, Union, New Jersey 07083 \\ ${ }^{5}$ Biological Sciences Department, California Polytechnic State University, San Luis Obispo, California 93407 \\ ${ }^{6}$ Center for Skin Biology, GlaxoSmithKline, Durham, North Carolina 27703 \\ ${ }^{7}$ STEM Program, Kean University, Union, New Jersey 07083 \\ ${ }^{8}$ Biomanufacturing Research Institute and Technology Enterprise, North Carolina Central University, Durham, \\ North Carolina 27707 \\ Correspondence: daina.zeng@gmail.com
}

\begin{abstract}
The glycopeptide antimicrobials are a group of natural product and semisynthetic glycosylated peptides that show antibacterial activity against Gram-positive organisms through inhibition of cell-wall synthesis. This is achieved primarily through binding to the Dalanyl-D-alanine terminus of the lipid II bacterial cell-wall precursor, preventing crosslinking of the peptidoglycan layer. Vancomycin is the foundational member of the class, showing both clinical longevity and a still preferential role in the therapy of methicillinresistant Staphylococcus aureus and of susceptible Enterococcus spp. Newer lipoglycopeptide derivatives (telavancin, dalbavancin, and oritavancin) were designed in a targeted fashion to increase antibacterial activity, in some cases through secondary mechanisms of action. Resistance to the glycopeptides emerged in delayed fashion and occurs via a spectrum of chromosome- and plasmid-associated elements that lead to structural alteration of the bacterial cell-wall precursor substrates.
\end{abstract}

$\mathrm{T}_{\mathrm{s}}^{\mathrm{h}}$ he glycopeptide antibiotics are a group of glycosylated cyclic or polycyclic nonribosomal peptides that inhibit Gram-positive bacterial cell-wall synthesis. Unlike other antimicrobial classes, these agents act as substrate binders (of cell-wall precursors) as opposed to active- site enzyme inhibitors (Barna and Williams 1984; Nagarajan 1994). Significant members of this class include vancomycin and the lipoglycopeptide teicoplanin, along with the semisynthetic lipoglycopeptide derivatives telavancin, dalbavancin, and oritavancin (Fig. 1). All

Editors: Lynn L. Silver and Karen Bush

Additional Perspectives on Antibiotics and Antibiotic Resistance available at www.perspectivesinmedicine.org

Copyright (C) 2016 Cold Spring Harbor Laboratory Press; all rights reserved; doi: 10.1101/cshperspect.a026989

Cite this article as Cold Spring Harb Perspect Med 2016;6:a026989 


\section{$8_{\mathrm{CSH}}^{\infty}$ Cold Spring Harbor Perspectives in Medicine \\ ERSPEC www.perspectivesinmedicine.org}
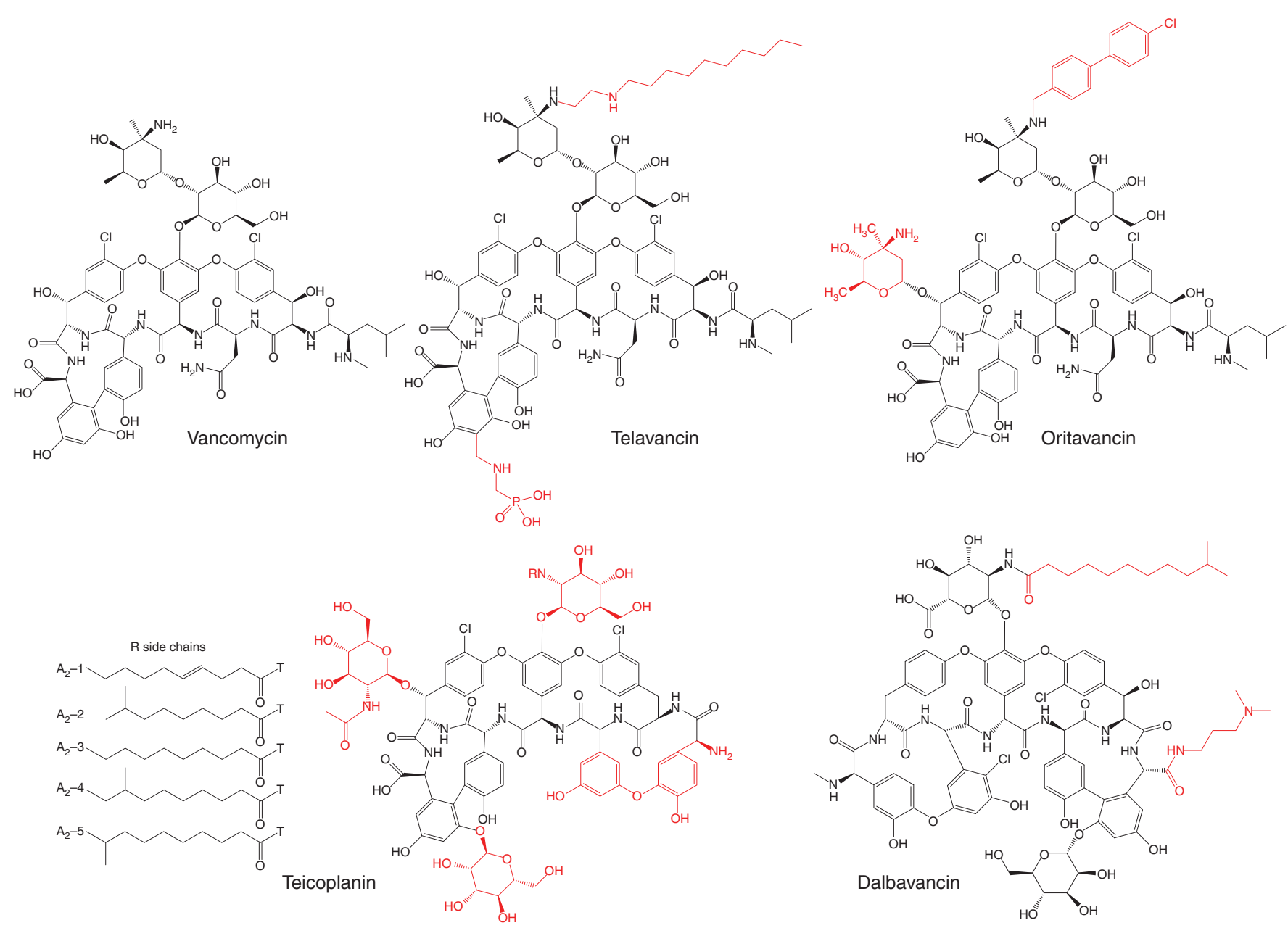

Figure 1. Glycopeptide and lipoglycopeptide antibacterial structures. Key structural features are highlighted in red. 
act to prevent cross-linking of the bacterial cellwall peptidoglycan layer by binding to the stochiometrically limited D-alanyl-D-alanine terminus of the lipid II monomer. Although the lipid II substrate is broadly expressed in most bacterial species, the antibacterial spectrum of this class is limited to Gram-positive pathogens. The physiochemical properties of the glycopeptide structure preclude transit through the outer membrane in Gram-negative species, thus blocking access to the lipid II target.

\section{STRUCTURE AND ORIGIN OF GLYCOPEPTIDE AGENTS}

Vancomycin (from the root word "vanquish") is the oldest glycopeptide antibiotic still in clinical use and has been named to the World Health Organization model list of essential medicines (see who.int/medicines/publications/essentialmedicines/EML2015_8-May-15.pdf). A natural product, vancomycin was isolated in 1953 from a strain of Amycolatopsis orientalis found in a soil sample (Nagarajan 1994; Kahne et al. 2005; Levine 2006) and first used clinically in 1955 with Food and Drug Administration (FDA) approval to treat penicillin-resistant staphylococci (McCormick et al. 1956). The glycopeptide class name derives from vancomycin's sugar-decorated heptapeptide structure, the hallmark of which is a central, highly cross-linked, multiring core that includes the polar uncharged amino acid asparagine and an amino-terminal $\mathrm{N}$-methylleucine (Fig. 1) (Harris and Harris 1982). Other amino acid positions are variable across species, differentiating many of the other natural product glycopeptides that have not been pursued as drug candidates (Nagarajan 1994). Also common across these agents is the terminal vancosamine moiety of the disaccharide substituent.

The related natural product, teicoplanin, was isolated $\sim 30$ years later from Actinoplanes teichomyceticus (Nagarajan 1994) and possesses a hydrophobic substituent that markedly differentiates its properties from vancomycin. Because of this difference, teicoplanin has been termed a lipoglycopeptide. Subsequent advanc- es in medicinal and organic chemistry have yielded novel semisynthetic lipoglycopeptide derivatives of teicoplanin, vancomycin, and related compounds that show improved activity against methicillin-resistant Staphylococcus aureus (MRSA) and are bactericidal for enterococci. Specifically, $N$-alkyl modifications of the amino sugars and alteration of the terminal carboxyl by amide derivatization (Fig. 1) improve antimicrobial activity of these agents without directly reducing lipid II binding (Allen et al. 1997; Leadbetter et al. 2004; Wenzler and Rodvold 2015).

Such clinically relevant lipoglycopeptide derivatives include the second-generation agents dalbavancin (BI-387) and oritavancin (LY-333328), and the third-generation agent telavancin (TD-6424) (Judice and Pace 2003; Pace et al. 2003; Zhanel et al. 2010; Karlowsky et al. 2015; Leuthener et al. 2015). Dalbavancin is derived structurally from teicoplanin; the addition of an extended, lipophilic side-chain results in enhanced potency and an extended halflife, whereas an amidated carboxyl side group results in enhanced antistaphylococcal activity (Fig. 1) (Smith et al. 2015). Oritavancin is a synthetic derivative of the naturally occurring glycopeptide chloroeremomycin (A82846B) (Nagarajan 1994; Linsdell et al. 1996). The addition of a $4^{\prime}$-chlorobiphenylmethyl substituent to the disaccharide sugar, along with the additional monosaccharide moiety (4-epivancosamine) attached to the amino acid residue on ring 6, confers significantly enhanced activity against vancomycin-resistant enterococci, and vancomycin-intermediate and -resistant staphylococci (Mitra et al. 2015). Telavancin was derived from $N$-decylaminoethylvancomycin by regioselective reductive alkylation of the vancosamine nitrogen. For telavancin, the addition of the negatively charged, auxiliary hydrophilic group methylaminophosphonic acid to the resorcinol position results in a substantial increase in urinary clearance and decrease in kidney and liver distribution when compared with the parent derivative, but the newer agent also shows diminished bactericidal activity versus the original precursor (Leadbetter et al. 2004; JL Pace, unpubl.). 
D. Zeng et al.

\section{ANTIBACTERIAL SPECTRUM}

Vancomycin possesses both in vitro and in vivo antibacterial activity against the clinically significant pathogens Staphylococcus spp., Streptococcus spp., susceptible Enterococcus spp., and many lesser species (Table 1). It is also bactericidal against $S$. aureus (including MRSA isolates) and the streptococci. This bactericidal activity led to the increased prevalence of vancomycin use as the incidence of multidrug-resistant MRSA burgeoned clinically, particularly before the approval of newer effective agents such as linezolid and the next-generation lipoglycopeptide agents. Because the physiochemical nature of the glyco- and lipoglycopeptide agents results in limited to no oral bioavailability, vancomycin has been restricted to parenteral administration, with the exception of oral (intraluminal) therapy against Clostridium difficile colitis.

Teicoplanin, which has been considered for development in this country but is currently only approved outside of the United States for clinical use, also possesses a Gram-positive antibacterial spectrum. However, in addition to the staphylococci, streptococci, other less signif- icant species, and vancomycin-susceptible enterococci, teicoplanin shows antibacterial activity against VanB (vancomycin-resistant) enterococci. The spectrum of the semisynthetic derivative dalbavancin is similar (Zhanel et al. 2010). In contrast, oritavancin and telavancin also show markedly improved activity against VanA enterococci, albeit of questionable clinical significance (Zhanel et al. 2010; Arias et al. 2012).

\section{MECHANISMS OF ACTION}

Early investigations into glycopeptide activity showed vancomycin-mediated inhibition of amino acid incorporation into bacterial peptidoglycan, with intracellular accumulation of metabolic precursors including the lipid carrier-linked $N$-acetyl-muramic pentapeptide (MurNAc-pentapeptide; lipid II) (Anderson et al. 1965; Chatterjee and Perkins 1966; Sinha and Neuhaus 1968; Perkins 1969). This suggested interference with the transglycosylation step of peptidoglycan assembly. Distribution studies with iodinated vancomycin showed that binding was surface-localized in the bacterial cell

Table 1. Glycopeptide and lipoglycopeptide antibacterial spectrum

\begin{tabular}{|c|c|c|c|c|c|}
\hline \multirow[b]{2}{*}{ Species } & \multicolumn{5}{|c|}{$\mathrm{MIC}_{50} / \mathrm{MIC}_{90}(\mu \mathrm{g} / \mathrm{mL}), \mathrm{ECOFF}$ or breakpoint } \\
\hline & Vancomycin & Teicoplanin & Telavancin & Oritavancin & Dalbavancin \\
\hline Staphylococcus aureus & $1 / 1^{\mathrm{a}}$ & $0.5 / 1^{\mathrm{b}}$ & $0.06 / 0.06^{\mathrm{c}}$ & $0.03 / 0.06^{\mathrm{d}}$ & $0.06 / 0.06^{\mathrm{e}}$ \\
\hline S. aureus (MRSA) & $1 / 2^{\mathrm{a}}$ & $1 / 2^{\mathrm{b}}$ & $0.06 / 0.06^{c}$ & $0.03 / 0.06^{\mathrm{d}}$ & $0.06 / 0.06^{\mathrm{e}}$ \\
\hline S. aureus (VISA) & $4-8^{\mathrm{f}}$ & $2^{\mathrm{g}}$ & $0.12 / 0.25^{\mathrm{c}}$ & $-/ 1^{\mathrm{h}}$ & $0.5 /-^{\mathrm{e}}$ \\
\hline Streptococcus pneumoniae & $0.25 / 0.5^{\mathrm{a}}$ & $0.12 / 0.12^{\mathrm{b}}$ & $0.008 / 0.015^{\mathrm{c}}$ & $0.002 / 0.004^{\mathrm{a}}$ & $0.015 / 0.03^{\mathrm{a}}$ \\
\hline Streptococcus pyogenes & $0.5 / 1^{\mathrm{a}}$ & $0.5^{\mathrm{g}^{\prime}}$ & $0.03 / 0.03^{\mathrm{c}}$ & $0.03 / 0.25^{\mathrm{d}}$ & $\leq 0.03 / \leq 0.03^{\mathrm{e}}$ \\
\hline Streptococcus agalactiae & $0.25 / 0.5^{\mathrm{a}}$ & $0.12 / 0.12^{\mathrm{b}}$ & $0.03 / 0.06^{\mathrm{c}}$ & $0.03 / 0.12^{\mathrm{d}}$ & $\leq 0.03 / 0.12^{\mathrm{e}}$ \\
\hline Streptococcus anginosus & & $0.12 / 0.12^{\mathrm{b}}$ & & $\leq 0.008 / 0.015^{\mathrm{d}}$ & $\leq 0.03 / \leq 0.03^{\mathrm{e}}$ \\
\hline Enterococcus faecium VSE & $0.5 / 1^{\mathrm{a}}$ & $0.25 / 1^{\mathrm{b}}$ & $\leq 0.015 / 0.03^{c}$ & $\leq 0.008 / 0.015^{\mathrm{d}}$ & $0.06 / 0.12^{\mathrm{e}}$ \\
\hline E. faecium VRE & $512 / 512^{\mathrm{a}}$ & $64 />64^{i}$ & $1 />1^{c}$ & $0.008 / 0.06^{\mathrm{d}}$ & $>4 />4^{\mathrm{e}}$ \\
\hline $\begin{array}{l}\text { VRE, Vancomycin-resistant } \\
\text { a Data from Zhanel et al. } 20 \\
{ }^{b} \text { Data from Gales et al. } 200 \\
{ }^{\mathrm{c}} \text { Data from Karlowsky et al. } \\
{ }^{\mathrm{d}} \text { Data from Mitra et al. } 201 \\
{ }^{\mathrm{e}} \text { Data from Smith et al. } 201 \\
{ }^{\mathrm{f}} \text { Data from CLSI 2016. } \\
{ }^{\mathrm{g}} \text { Data from EUCAST } 2015 . \\
{ }^{\mathrm{h}} \text { Data from Das et al. } 2013 . \\
{ }^{\mathrm{i}} \text { Data from Shonekan et al. }\end{array}$ & $\begin{array}{l}\text { Enterococcus; VSE } \\
0 . \\
2015 . \\
. \\
.\end{array}$ & vancomycin-su & ceptible Enterococ & & \\
\hline
\end{tabular}


(Bordet and Perkins 1970; Perkins and Nieto 1970; Nieto and Perkins 1971). Further, it was observed that vancomycin complexed with lipid II, and that peptidoglycan synthesis in Gaffkyia homari (which uses a distinct, tetrapeptidelinked precursor) was not inhibited (Hammes and Neuhaus 1974). Subsequently, it was concluded that vancomycin binds to the D-alanylD-alanine terminating pentapeptide moiety of lipid II, preventing both transpeptidation through substrate sequestration and transglycosylation via associated steric hindrance. The binding of vancomycin to the D-alanyl-D-alanine terminating pentapeptide is mediated by hydrogen binding (Table 2) (Cristofaro et al. 1995; Cooper et al. 1997, 2000; Cooper and Williams 1999; Walsh and Howe 2002).

In addition to the very distinct mechanism of substrate sequestration mediating its antibacterial properties, vancomycin's activity is influenced by noncovalent self-association of the antibiotic molecules (Gerhard et al. 1993; Mackay et al. 1994b; Beauregard et al. 1995; Westwell et al. 1996). Using a variety of antibiotic analogues and substrate proxies as models, the dimerization of vancomycin was determined to be promoted in part by interaction with the lipid II target (Mackay et al 1994a; Sharman et al. 1997; Loll et al. 1998, 2009). This antibiotic self-association is believed to be entropically beneficial and actually results in orders of magnitude greater affinity, as binding to a second lipid II moiety then requires lower energy because of colocalization (Williams et al. 1993, 1998; Rao et al. 1999a,b; Rekharsky et al. 2006). Cocrystalization studies with vancomycin and substrate target confirm a conformation of what are termed back-to-back dimers (vancosamine-vancosamine $[\mathrm{V}-\mathrm{V}])$; in addition, there can be association of a third vancomycin molecule in a side-side configuration (Williamson and Williams 1981; Schaefer et al 1996; Loll et al 1997; Nitani et al. 2009). Studies with synthetic, covalently linked dimers further support these conclusions, with the $\mathrm{V}-\mathrm{V}$ constructs showing the broadest in vitro antibacterial activity, often superior to that of vancomycin itself (Sundram et al. 1996; Rao et al. 1998; Stack et al. 1998; Staroske and Williams 1998; Arimoto et al. 1999; Nicolau et al. 2001a,b; Griffin et al. 2003; Shiozawa et al. 2003; Li and Xu 2005).

Vancomycin also antagonizes peptidoglycan remodeling, or "autolysis" (Sieradzki and Tomasz 1997; Peschel et al. 2000). The importance of this antagonism may explain the lack of bactericidal activity against otherwise susceptible enterococci, as these species show a low autolytic capacity. Almost certainly, the balance of effects on peptidoglycan synthesis (anabolism) and remodeling (autolysis, catabolism) is critical to antibacterial success for cell-wall inhibitors like the glycopeptides. This mechanism also likely mediates the concentration-independent bactericidal nature of vancomycin against the staphylococci; in fact, with some of the synthetic, covalently linked, vancomycin dimer analogues, treatment of bacteria with higher antibiotic concentrations leads to greater numbers of surviving cells (JL Pace, unpubl.).

Teicoplanin, like vancomycin, mediates its antibacterial activity by binding to the Dalanyl-D-alanine moiety and sequestration of the lipid II substrate, resulting in inhibition of bacterial peptidoglycan synthesis (Barna et al.

Table 2. Glyccopeptide and lipoglycopeptide mechanism(s) of action

\begin{tabular}{|c|c|c|c|c|}
\hline \multirow[b]{3}{*}{ Antibiotic } & \multicolumn{4}{|c|}{ Mechanism } \\
\hline & \multicolumn{2}{|c|}{ Lipid II-binding } & \multirow{2}{*}{$\begin{array}{l}\text { Transpeptidation } \\
\text { (enzymatic) }\end{array}$} & \multirow{2}{*}{$\begin{array}{c}\text { Membrane (permeabilization- } \\
\text { depolarization) }\end{array}$} \\
\hline & Dimerization & Membrane anchoring & & \\
\hline Vancomycin & Yes & No & No & No \\
\hline Teicoplanin & No & Yes & No & No \\
\hline Dalbavancin & No & Yes & No & No \\
\hline Oritavancin & Yes & Yes & Yes & Yes \\
\hline Telavancin & Yes & Yes & Unknown & Yes \\
\hline
\end{tabular}


D. Zeng et al.

1985; Nagarajan 1994; Beauregard et al. 1995). Importantly, distinct structural differences impact the self-associated dimer formation that is important for vancomycin target affinity but absent with teicoplanin. In contrast, a second evolutionarily beneficial property has been imparted to teicoplanin, which minimizes the lack of dimerization potential (Barna et al. 1985; Beauregard et al. 1995). The hydrophobic moiety of teicoplanin interacts with the lipid bilayer of the bacterial membrane resulting in localization (anchoring) in proximity to the lipid II substrate, thus also providing a potentially energetically favorable interaction that mediates antibacterial action (Barna et al. 1985; Beauregard et al. 1995; Economou et al. 2013). Likewise, dalbavancin mechanism of action is believed to be similar to that of teicoplanin.

Oritavancin, however, has additional mechanisms of action. The hydrophobic $4^{\prime}$-chlorobiphenylmethyl side chain on the disaccharide sugar of oritavancin facilitates direct interaction with the bacterial cell membrane, providing additional stability during oritavancin's interaction with lipid II (Allen and Nicas 2003). Oritavancin can also bind to D-alanyl-D-lactate, and this affinity is enhanced by its ability to form noncovalent dimers before attachment to the bacterial peptidoglycan cell wall. This dimerization is possible because of interactions between the disaccharides attached to residue 4, the chlorine on ring 2, and the 4-epi-vancosamine on ring 6 , also found with the underivatized natural product chloroeremomycin (A28246B), which already shows superior dimerization to vancomycin (Linsdell et al. 1996; Allen et al. 2002). In addition to the above, oritavancin has been reported to inhibit transpeptidation. This action is attributed to the $4^{\prime}$-chlorobiphenylmethyl side chain, which allows binding of the drug to the pentaglycyl bridge, a secondary site in peptidoglycan, and likely contributes to oritavancin's activity against vancomycin-intermediate $S$. aureus (VISA) and vancomycin-resistant Enterococcus isolates (Leimkuhler et al. 2005; Mitra et al. 2015). The $4^{\prime}$-chlorobiphenylmethyl side chain of the molecule is also credited for Gram-positive bacterial cell death via membrane depolarization and increased mem- brane permeability. This mechanism, which leads to disruption of membrane ultrastructure, has been shown in vitro to effect both antibacterial activity against stationary-phase inocula of staphylococci and rapid killing of susceptible Gram-positive pathogens. Interestingly, oritavancin additionally shows activity against S. aureus biofilms in vitro (Belley et al. 2009). Finally, oritavancin may also have some effect on inhibition of RNA synthesis but a direct effect is questionable (Allen and Nicas 2003).

Telavancin differs from vancomycin by having a dual mechanism of action, thought to be responsible for its rapid, dose-dependent bactericidal activity (Higgins et al. 2005). Like vancomycin and the other members of this class, telavancin has a glycopeptide core that binds with high affinity to the D-alanyl-D-alanine terminus of cell-wall precursors through a network of hydrogen bonds and hydrophobic packing interactions (Karlowsky et al. 2015). Thus, telavancin inhibits synthesis of peptidoglycan by binding to late-stage precursors. This binding prevents both polymerization of the lipid II precursor and subsequent cross-linking (Lunde et al. 2009). In contrast to vancomycin, telavancin does not inhibit autolysis (JL Pace, unpubl.). However, like oritavancin, telavancin does bind to bacterial cell membranes and cause a rapid, concentration-dependent depolarization of the plasma membrane, increased permeability, and leakage of cellular adenosine triphosphate and potassium (Higgins et al. 2005). The timing of these membrane changes correlates with the rapid, concentration-dependent bacterial killing seen with this agent, suggesting that telavancin's bactericidal activity results from the dissipation of cell membrane potential and an increase in membrane permeability (Higgins et al. 2005). Telavancin is also 10 times more active than vancomycin in inhibiting both the transglycosylation and the synthesis of peptidoglycan because of its ability to bind to bacterial cell membranes (Debabov et al. 2002; Higgins et al. 2005; Lunde et al. 2009). An alternative mechanism has been proposed for lipoglycopeptides suggesting that the liposaccharide elements of lipoglycopeptides interact directly with and inhibit transglycosylase enzymes that 
mediate the polymerization of precursors into immature, un-cross-linked peptidoglycan (Ge et al. 1999; Goldman et al. 2000; Kerns et al. 2002; Chen et al. 2003); however, in the case of telavancin, this mechanism is not supported by observations that inhibition of transglycosylase is completely antagonized by the cell-wallmimicking tripeptide dKAA (Higgins et al. 2005). Finally, it is hypothesized that telavancin inhibits bacterial lipid synthesis (Debabov et al. 2002).

\section{MECHANISMS OF RESISTANCE}

Gram-negative bacilli are intrinsically resistant to vancomycin and lipoglycopeptides, because the presence of the outer membrane prevents these large, complex molecules from entering the cell and binding to their target sites. In Gram-positive bacteria, the onset of vancomycin resistance was long delayed compared with that for other nonglycopeptide antibiotics. The first vancomycin-resistant clinically isolated strain was reported in 1987, more than 30 years after the introduction of vancomycin (Leclercq et al. 1988). Today more than $30 \%$ of intensive care unit (ICU) Enterococcus faecalis infections are vancomycin-resistant Enterococcus (VRE) and, following the emergence of vancomycin resistance in Enterococcus, rapid resistance developed in S. aureus (VRSA) as a result of horizontal gene transfer from resistant enterococci (Nebreda et al. 2007; Werner et al. 2008; Zhu et al. 2010; Fernandes et al.2015). The first fully VRSA strain (vancomycin, minimum inhibitory concentration $[\mathrm{MIC}]>256 \mu \mathrm{g} / \mathrm{mL}$; teicoplanin, $\mathrm{MIC}=128 \mu \mathrm{g} / \mathrm{mL}$ ) was reported in 2002 (Howden et al.2010) with an increasing number of cases each year in the United States (Walters et al. 2015).

Because vancomycin forms complexes with peptidoglycan precursors, its activity is determined by its binding affinity to precursor substrates. Indeed, the main mechanism of resistance to vancomycin is owing to the presence of enzymes that produce lower-affinity binding precursors in which the carboxy-terminal D-alanine residue is replaced by either D-lactate, resulting in a 1000-fold decrease in binding affin- ity caused by the loss of a hydrogen bond interaction (Pootoolal et al. 2002), or D-serine, resulting in a sixfold loss of binding affinity likely caused by steric hindrance. There are six different molecular resistance elements that confer resistance to vancomycin by altering the structure of the peptidoglycan precursors (Table 3) (Cetinkaya et al. 2000; Courvalin 2006).

Van-A type resistance is the most frequently encountered mechanism of resistance in enterococci and is the only one detected in S. aureus to date (Perichon and Courvalin 2009). Transposon Tn1546 and closely related elements encoding nine polypeptides responsible for vancomycin resistance mediate this by changing the carboxyl terminus peptidoglycan precursor from D-alanine to D-lactate. These proteins include those needed for the synthesis of modified peptidoglycan precursors (VanH and VanA), hydrolysis of normal precursors (VanX and VanY), regulation of expression of resistance (VanR and VanS), transposition (products of ORF1 and ORF2), and an unknown function (VanZ). VanH is a dehydrogenase that reduces pyruvate to D-Lac, and VanA is a ligase allowing the formation of a D-Ala-D-Lac depsipeptide that replaces the D-Ala-D-Ala dipeptide. Furthermore, indigenous concentrations of D-AlaD-Ala are reduced by VanX and VanY. VanX is a $\mathrm{D}, \mathrm{D}$-dipeptidase that hydrolyzes the D-Ala-D-Ala formed by the host chromosomal D-Ala-D-Ala ligase, and VanY is a D,D-carboxypeptidase that hydrolyzes the terminal D-Ala of pentapeptide precursors that are produced if elimination of the D-Ala-D-Ala is not complete (Arthur et al. 1996). Inducible expression of this resistance is regulated by the VanR/VanS two-component system. VanS is the membrane-associated sensor that is activated by the presence of glycopeptides and transfers a phosphoryl group to VanR, which is the response regulator that activates the cotranscription of the vanH, vanA, vanX, and van $Y$ genes by binding to the $\mathrm{P}_{\mathrm{RES}}$ promoter (Arthur et al. 1992), and of the vanR and vanS genes by binding to the $\mathrm{P}_{\mathrm{REG}}$ promoter (Depardieu et al. 2007). This transposition confers high-level resistance to vancomycin and teicoplanin as well as telavancin, although telavancin 


\section{$\$_{\mathrm{CSH}}^{\infty}$ Cold Spring Harbor Perspectives in Medicine \\ PESPECTIVES www.perspectivesinmedicine.org}

Table 3. Glycopeptide and lipoglycopeptide antibacterial resistance determinants (Courvalin 2006)

\begin{tabular}{|c|c|c|c|c|c|c|c|c|}
\hline \multirow[b]{2}{*}{ Resistance type } & \multirow{2}{*}{$\begin{array}{c}\text { Resistance } \\
\text { element }\end{array}$} & \multirow[b]{2}{*}{ Expression } & \multirow[b]{2}{*}{ Location } & \multirow[b]{2}{*}{ Modified target } & \multicolumn{4}{|c|}{$\mathrm{MIC}(\mu \mathrm{g} / \mathrm{mL})$} \\
\hline & & & & & Vancomycin & Teicoplanin & Oritavancin & Telavancin \\
\hline Van-A & $\operatorname{Tn} 1546$ & Inducible & Plasmid & $\begin{array}{l}\text { D-alanine } \\
\text { D-lactate }\end{array}$ & $64-1000$ & $16-512$ & $8-16^{\mathrm{a}}$ & $32^{\mathrm{a}}$ \\
\hline Van-B & $\operatorname{Tn} 1547$ or $\operatorname{Tn} 1549$ & Inducible & Plasmid & $\begin{array}{l}\text { D-alanine } \\
\text { D-lactate }\end{array}$ & $4-1000$ & $0.5-1$ & $8-16^{\mathrm{a}}$ & \\
\hline Van-C & & $\begin{array}{l}\text { Constitutive } \\
\text { Inducible }\end{array}$ & Chromosome & $\begin{array}{l}\text { D-alanine } \\
\text { D-serine }\end{array}$ & $2-32$ & $0.5-1$ & $8-16^{\mathrm{a}}$ & \\
\hline Van-D & & Constitutive & Chromosome & $\begin{array}{l}\text { D-alanine } \\
\text { D-lactate }\end{array}$ & $64-128$ & $4-64$ & & \\
\hline Van-E & & Inducible & Chromosome & $\begin{array}{l}\text { D-alanine } \\
\text { D-serine }\end{array}$ & $8-32$ & 0.5 & & \\
\hline Van-G & & Inducible & Chromosome & $\begin{array}{l}\text { D-alanine } \\
\text { D-serine }\end{array}$ & 16 & 0.5 & & \\
\hline
\end{tabular}

${ }^{\mathrm{a}}$ Selected in resistance passaging studies. 
MICs remain 32- and 128-fold lower compared with those of vancomycin and teicoplanin (Karlowsky et al. 2015). The VanA-type resistance is transmittable from Enterococcus species to $S$. aureus and is the main resistance mechanism for VRSA (Perichon and Courvalin 2009).

Like VanA, VanB-type resistance is caused by the presence of a tranposition ( $\operatorname{Tn} 1547$ or Tn1549), resulting in the altered synthesis of the depsipeptide D-Ala-D-Lac to replace the dipeptide D-Ala-D-Ala and leading to decreased lipid II binding by the antimicrobials. Also, the organization and functionality of the vanB cluster are similar to that of van $\mathrm{A}$, encoding a dehydrogenase, ligase, and a dipeptidase, all of which have a high level of sequence identity $(67 \%-76 \%)$ to the corresponding proteins of the vanA operon. However, the regulatory proteins in VanB type resistance only distantly relate to VanRS (34\% and 24\% identity) and are only induced by vancomycin but not teicoplanin; hence, strains with this phenotype have high-level resistance only to vancomycin (Courvalin 2006).

Likewise, VanD-type resistance also results in the production of peptidoglycan precursors ending in D-Ala-D-Lac. The organization of the vanD operon is similar to that of vanA and vanB; however, vanD is located exclusively on the bacterial chromosome and resistance is not transferable by conjugation to other enterococci (Depardieu et al. 2004). In addition, VanD-type strains do not have D,D-dipeptidase activity, which is not needed because various point mutations also result in null D-Ala-D-Ala ligase activity (Arthur et al. 1998; Depardieu et al. 2003b). Interestingly, because of this defect in indigenous D-Ala-D-Ala production, VanDtype strains require constitutive expression of these resistance elements to survive and achieve this via mutations in the $\operatorname{VanS}_{\mathrm{D}}$ sensor or $\operatorname{VanR}_{\mathrm{D}}$ regulator (Depardieu et al. 2003b, 2004).

The VanC-type resistance is found in Enterococcus gallinarum, Enterococcus casseliflavus, and Enterococcus flavescens and results in production of peptidoglycan precursors terminating in D-Ala-D-Ser (Reynolds and Courvalin 2005). This cluster contains three main genes that are needed to confer resistance: VanT is a membrane-bound serine racemase that produces D-Ser; VanC is a ligase that catalyzes synthesis of D-Ala-D-Ser; and VanXY $\mathrm{C}_{\mathrm{C}}$ possesses both D,Ddipeptidase and D,D-carboxypeptidase activities and hydrolyzes precursors ending in D-Ala-DAla. The VanC phenotype is expressed constitutively or inducibly on the chromosome and confers resistance to low levels of vancomycin but not to other glycopeptides (Reynolds and Courvalin 2005).

VanE-type resistance is organized similarly to VanC and is found in intrinsically resistant E. faecalis. Unlike VanC, the VanE phenotype is only inducibly expressed (Courvalin 2006).

The VanG-type resistance consists of genes from various van operons: VanG is a D-AlaD-Ser ligase (similar to VanC-type strains); $\operatorname{VanXY}_{\mathrm{G}}$ is a putative bifunctional D,D-peptidase and D,D-carboxypeptidase; $\operatorname{VanT}_{\mathrm{G}}$ is a serine racemase (similar to VanE-type strains); and $\operatorname{VanR}_{\mathrm{G}}$ and $\operatorname{VanS}_{\mathrm{G}}$ make up the two component regulatory response proteins (highest similarity to the VanD-type strains). Like VanC and VanE phenotypes, the VanG-type strains produce DAla-D-Ser and only have intermediate-level resistance to vancomycin (Depardieu et al. 2003a).

VISA strains, unlike those described above, do not carry imported foreign genetic elements; rather, resistance occurs owing to mutations that appear in the invading pathogen during treatment. Although the MIC value of these strains are modest $(\mathrm{MIC}=2-16 \mu \mathrm{g} / \mathrm{mL})$, vancomycin treatment of VISA infections often ends in treatment failure (Linares 2001; Fridkin et al. 2003). Most commonly, these strains have emerged in patients with MRSA infections undergoing prolonged vancomycin therapy ( $\mathrm{Li}$ nares 2001; Chen et al. 2003; Howden et al. 2010). Although VISA isolates have differing point mutations, they do share common abnormal properties including increased cell-wall material, an aberrant separation of daughter cells at the end of cell division, and altered (usually decreased) rates of autolysis (Hiramatsu 2001; Walsh and Howe 2002; Sieradzki and Tomasz 2003; Pfeltz and Wilkinson 2004; Gardete et al. 2012; Howden et al. 2014; Karlowsky et al. 2015). The most frequent genetic changes in VISA strains are in walkR and vraSR (two- 
D. Zeng et al.

component sensory regulatory system controlling the transcription of genes in cell-wall synthesis), and rpoB (RNA polymerase) genes (Howden et al. 2008, 2011; Kato et al. 2010; Watanabe et al. 2011; Hafer et al. 2012). It is hypothesized that these point mutations decrease the cross-linking of peptidoglycan strands, which results in an increase in the number of free D-Ala-D-Ala residues in the cell wall that bind and sequester vancomycin (Sieradzki et al. 1999; Hiramatsu 2001; Sieradzki and Tomasz 2003). These D-Ala-D-Ala residues can be maintained in the mature peptidoglycan because of low carboxypeptidase activity, and vancomycin-resistant laboratory mutants have shown an increased capacity to bind vancomycin in their cell walls (Sieradzki and Tomasz 1997). Not only does this result in "decoy" targets, but binding of the large glycopeptide molecules would further hinder the progress of the antibiotic through the mesh-like cell wall to its lethal target, the lipid-linked peptidoglycan precursor, thus creating a "drug capture" (Perichon and Courvalin 2009) and "clogging" phenomenon (Sieradzki et al. 1999).

Reported in vitro mutational frequency of resistance against dalbavancin, oritavancin, and telavancin has been remarkably, although not unexpectedly, limited (Arthur et al. 1999; Krause et al. 2005; Sahm et al. 2006; Goldstein et al. 2007; Laohavaleeson et al. 2007; KosowskaShick et al. 2009; Song et al. 2013). Resistance to vancomycin required $\sim 30$ years in the clinic to become prevalent and required concomitant acquisition of several exogenous genes. With the semisynthetic lipoglycopeptide antimicrobials showing additional mechanisms of action, resistance frequency is expected to be lower.

Like teicoplanin, telavancin retains activity against strains that express vanB, but not van $A$ as it induces expression of the latter (Zhanel et al. 2010). In a study by Kosowska-Shick and colleagues that serially passaged 10 strains of MRSA to evaluate the potential for emergence of resistance, spontaneous mutants resistant to telavancin were detected in only 1 of the 10 MRSA strains tested. The MIC for that strain increased from 0.25 to $2 \mu \mathrm{g} / \mathrm{mL}$ after 43 days of serial passaging; no further increase in the
MIC of this mutant occurred when serial passaging was continued to a maximum of 50 days (Kosowska-Shick et al. 2009). In another study, six species of Gram-positive bacteria, including S. aureus, vancomycin-resistant enterococci, and multidrug-resistant Streptococcus pneumoniae, were exposed to sub-MIC concentrations of telavancin for 10 days to attempt to isolate resistant mutants. However, this failed to produce any organisms that were resistant to telavancin; mutation frequencies were $<1 \times 10^{-9}$ for all isolates tested (Sahm et al. 2006). Laohavaleeson et al. (2007) also reported that telavancin showed a low frequency of spontaneous resistance among staphylococci and enterococci, with low spontaneous resistance rates for S. aureus strains and both VanA E. faecalis and Enterococcus faecium $\left(<1 \times 10^{-9}\right.$ and $<1 \times$ $10^{-7}$, respectively). Similarly, Krause et al. (2005) reported telavancin to have a low potential for resistant-mutant selection among S. aureus (MSSA, MRSA) and vancomycinsusceptible enterococci because it failed to select mutants with MICs $>4$ times those of parental strains following 20 passages. Two mutants with telavancin MICs 4 times that of the parental strain $(32 \mu \mathrm{g} / \mathrm{mL})$ were selected from vancomycin-resistant enterococci strains (VanA) used; mutant phenotypes were stable on extended subculture, and no changes were observed in growth properties of isolates with reduced susceptibility to telavancin. Song et al. (2013) sought to determine mechanisms of decreased telavancin susceptibility in a laboratory-derived mutant of $S$. aureus, TlvDSMED1952, and showed extensive changes in the mutant transcriptome compared with the susceptible parent strain, MED1951. Upregulated genes in TlvDSMED1952 included cofactor biosynthesis genes, cell-wall-related genes, fatty acid biosynthesis genes, and stress genes, whereas down-regulated genes included lysine operon biosynthesis genes and $\operatorname{lrg} B$ (induced by telavancin in susceptible strains), $a g r$ and $k d p D E$ genes, various cell surface protein genes, phenol-soluble modulin genes, several protease genes, and genes involved in anaerobic metabolism. The investigators reported that TlvDSMED1952 showed various features simi- 
lar to VISA and strains with decreased daptomycin susceptibility, but also showed its own unique features. Consistent with these findings was that in vitro resistance was more frequently selected in VanA E. faecalis, and that an increased $\mathrm{IC}_{50}$ for $\left[{ }^{14} \mathrm{C}\right]$-acetate incorporation into both cellular phospholipids and saponifiable fatty acids appeared to correlate with the increased MICs, whereas peptidoglycan synthesis inhibition was unchanged (Debabov et al. 2002; Higgins et al. 2005; JL Pace, unpubl.). Heteroresistance has not been detected in isolates of $S$. aureus, nor has resistance been detected in isolates of $S$. aureus or S. pneumoniae collected either through clinical trials or through global surveillance (Kosowska-Shick et al. 2009; Krause et al. 2012). MIC90 values of $0.25-0.5 \mu \mathrm{g} / \mathrm{mL}$ (S. aureus isolates including MRSA) and $0.03 \mu \mathrm{g} / \mathrm{mL}$ (S. pneumoniae) have been reported (Theravance 2014).

Similar to teicoplanin and telavancin, dalbavancin resistance is observed for strains that express the vanA operon, but not vanB, as this agent only induces expression of the former. Prospective worldwide surveillance from 2002 to 2012 of the in vitro potency of dalbavancin against $>150,000$ Gram-positive isolates found no evidence of glycopeptide-resistant or glycopeptide intermediate $S$. aureus by CLSI criteria ( $\mathrm{MIC}_{90}$ was $0.06 \mu \mathrm{g} / \mathrm{mL}$ for $S$. aureus). Isolates from phase-III clinical trials showed similar susceptibility profiles to those detailed in the surveillance studies (Jones et al. 2013a,b). The potential for staphylococci to develop resistance to dalbavancin was studied by Goldstein et al. (2007) by means of direct selection and by serial passage at subtherapeutic concentrations. In direct selection experiments with the six strains tested (one MSSA strain, three MRSA strains, one VISA strain, and one methicillinresistant $S$. epidermidis strain), no colonies with increased MICs were obtained on dalbavancincontaining plates (frequency $<10^{10}$ ). The same six strains were passaged in the presence of subinhibitory concentrations of dalbavancin. After 20 passages, four strains (including the VISA strain) had a dalbavancin MIC that was within one doubling dilution of the MIC obtained before the 20 passages. For two MRSA strains, increases of two or three dilutions were seen (to 0.25 and $0.5 \mu \mathrm{g} / \mathrm{mL}$ ). When these isolates were grown on drug-free medium for 3 consecutive days and retested, the MICs were equivalent or within one doubling dilution of the starting MICs.

Oritavancin resistance among clinical isolates has not been detected so far (Allen and Nicas 2003). However, a moderate level of resistance ( $\mathrm{MIC} \leq 16 \mu \mathrm{g} / \mathrm{mL}$ ) to the drug has been observed in the laboratory among Enterococcus isolates showing the VanA and VanB phenotypes and can occur by various mechanisms (Arthur et al. 1999). Total replacement of the peptidoglycan precursors terminating in D-alanine by isolates capable of producing peptidoglycan precursors terminating in D-lactate can confer resistance to oritavancin. This can be achieved in vitro by either increasing resistance gene expression or reducing production of D-Ala-D-Ala. Resistance to the drug may also occur with expression of the vanZ gene. Additionally, mutations in the vanSB sensor gene of the vanB cluster confer cross-resistance to teicoplanin and oritavancin (Arthur et al. 1999), making it is quite likely that emergence of resistance to oritavancin may occur with widespread clinical use.

\section{CONCLUDING REMARKS}

Over the past 60 years, vancomycin has come to play a critical, lifesaving role in a physician's armamentarium against serious Gram-positive bacterial infections. This antibiotic's remarkable longevity of use and delayed onset of resistance speaks to the unique mode of action of the glycopeptide antibiotic class. Since 2011, three semisynthetic lipoglycopeptide antibacterials have gained FDA approval in the United States. The development of these new agents was guided by the extensive body of earlier research on vancomycin-its mechanism of action, mechanisms of resistance, and therapeutic applications. These targeted efforts have imparted new, beneficial properties to the glycopeptide class. One can only hope that, through stewardship and appropriate practice, the successful clinical use of vancomycin and the newer gly- 
D. Zeng et al.

copeptide agents will continue far into the future, to the benefit of all.

\section{ACKNOWLEDGMENTS}

Dr. Dmitri Debabov worked on this review before his employment at Allergan, and the opinions stated within do not represent those of Allergan.

\section{REFERENCES}

Allen NE, Nicas TI. 2003. Mechanism of action of oritavancin and related glycopeptide antibiotics. FEMS Microbiol Rev 26: 511-532.

Allen NE, LeTourneau DL, Hobbs N. 1997. Role of hydrophobic side chains as determinants of antibiotic activity of semi-synthetic glycopeptide antibiotics. J Antibiot 50: 677-684.

Allen NE, LeTourneau DL, Hobbs N, Thompson RC. 2002. Hexapeptide derivatives of glycopeptide antibiotics: Tools for mechanism of action studies. Antimicrob Agents Chemother 46: 2344-2348.

Anderson JS, Matsuhashi M, Haskin MA, Strominger JL. 1965. Lipid-phosphoacetylmuramyl-pentapeptide and lipid-phosphodisaccharide-pentapeptide: Presumed membrane transport intermediates in cell wall synthesis. Proc Natl Acad Sci 53: 881-889.

Arias CA, Mendes RE, Stilwell MG, Jones RN, Murray BE. 2012. Unmet needs and prospects for oritavancin in the management and vancomycin-resistant enterococcal infections. Clin Infect Dis 54: S233-S238.

Arimoto HK, Nishimura K, Hayakawa I, Kinumi T, Uemura D. 1999. Multi-valent polymer of vancomycin: Enhanced activity against VRE. Chem Commun 1361-1362.

Arthur M, Molinas C, Courvalin P. 1992. The VanS-VanR two-component regulatory system controls synthesis of depsipeptide peptidoglycan precursors in Enterococcus faecium BM4147. J Bacteriol 174: 2582-2591.

Arthur M, Reynolds P, Courvalin P. 1996. Glycopeptide resistance in enterococci. Trends Microbiol 4: 401407.

Arthur M, Depardieu F, Cabanié L, Reynolds P, Courvalin P. 1998. Requirement of the VanY and VanX D,D-peptidases for glycopeptide resistance in enterococci. Mol Microbiol 30: $819-830$.

Arthur M, Depardieu F, Reynolds P, Courvalin P. 1999. Moderate-level resistance to glycopeptide LY333328 mediated by genes of the van $A$ and $v a n B$ clusters in enterococci. Antimicrob Agents Chemother 43: 1875-1880.

Barna JCJ, Williams DH. 1984. The structure and mode of action of glycopeptide antibiotics of the vancomycin group. Annu Rev Microbiol 38: 339-357.

Barna JCJ, Williams DH, Williamson MI. 1985. Structural features that affect the binding of teicoplanin, ristocetin $\mathrm{A}$, and their derivatives to bacterial cell wall model $\mathrm{N}$ acetyl-D-alaynyl-D-alanine. J Chem Soc Chem Commun 5: $254-256$.
Beauregard DA, Williams DH, Gwynn MN, Knowles DJC. 1995. Dimerization and membrane anchors in extracellular targeting of vancomycin group antibiotics. Antimicrob Agents Chemother 39: 781-785.

Belley AE, Neesham-Grenon E, McKay G, Arhin FF, Harris R, Beveridge T, Parr TR, Moeck G. 2009. Oritavancin kills stationary-phase and biofilm Staphylococcus aureus cells in vitro. Antimicrob Agents Chemother 53: 918-925.

Bordet C, Perkins HR. 1970. Iodinated vancomycin and mucopeptide biosynthesis by cell-free preparations from Micrococcus lysodeikticus. Biochem J 119: 877-883.

Cetinkaya YP, Falk P, Mayhall CG. 2000. Vancomycin-resistant enterococci. Clin Microbiol Rev 13: 686-707.

Chatterjee AN, Perkins HR. 1966. Compounds formed between nucleotides related to the biosynthesis of bacterial cell wall and vancomycin. Biochem Biophys Res Commun 24: 489-494.

Chen LD, Walker D, Sun B, Hu Y, Walker S, Kahne D. 2003. Vancomycin analogues active against vanA-resistant strains inhibit bacterial transglycosylase without binding substrate. Proc Natl Acad Sci 100: 5658-5663.

CLSI. 2016. Performance Standards for Antimicrobial Susceptibility Testing. CLSI supplement M100S26, 26th ed. Clinical and Laboratory Standards Institute, Wayne, PA.

Cooper MA, Williams DH. 1999. Binding of glycopeptide antibiotics to a model of a vancomycin-resistant bacterium. Chem Biol 6: 891-899.

Cooper MA, Williams DH, Cho YR. 1997. Surface plasmon resonance analysis of glycopeptide antibiotic activity at a model membrane surface. Chem Commun 1625-1626.

Cooper MA, Fiorini MT, Abell C, Williams DH. 2000. Binding of vancomycin group antibiotics to D-alanine and Dlactate presenting self-assembled monolayers. Bioorg Med Chem 8: 2609-2616.

Courvalin P. 2006. Vancomycin resistance in Gram-positive cocci. Clin Infect Dis 42: S25-S34.

Cristofaro MF, Beauregard DA, Yan H, Osborn NJ, Williams DH. 1995. Cooperativity between non-polar and ionic forces in the binding of bacterial cell wall analogues by vancomycin in aqueous solution. J Antibiotics 48: 805810.

Das B, Sarkar C, Schachter J. 2013. Oritavancin-A new semisynthetic lipoglycopeptide agent to tackle the challenge of resistant Gram-positive pathogens. Pak J Pharm Sci 26: 1045-1055.

Debabov DPJ, Kaniga K, Nodwell M, Farrington L, Campbell B, Karr D, Leadbetter M, Linsell M, Wu T, Krause K, et al. 2002. A novel bactericidal antibiotic inhibits bacterial lipid synthesis. Interscience Conference on Antimicrobial Agents and Chemotherapy. San Diego, CA, September 27-30.

Depardieu F, Bonora MG, Reynolds PE, Courvalin P. 2003a. The vanG glycopeptide resistance operon from Enterococcus faecalis revisited. Mol Microbiol 50: 931-948.

Depardieu F, Reynolds PE, Courvalin P. 2003b. VanD-type vancomycin-resistant Enterococcus faecium 10/96A Antimicrob Agents Chemother 47: 7-18.

Depardieu FM, Kolbert M, Pruul H, Bell J, Couvalin P. 2004. VanD-type vancomycin-resistant Enterococcus faecium and Enterococcus faecalis. Antimicrob Agents Chemother 48: 3892-3904. 
Depardieu F, Podglajen I, Leclercq R, Collatz E, Couvalin P. 2007. Modes and modulations of antibiotic resistance gene expression. Clin Microbiol Rev 20: 79-114.

Economou NJ, Zentner IJ, Lazo E, Jakoncic J, Stojanoff V, Weeks SD, Grasty KC, Cocklin S, Loll PJ. 2013. Structure of the complex between teicoplanin and a bacterial cellwall peptide: Use of a carrier-protein approach. Acta Crystallogr D Biol Crystallogr 69: 520-533.

European Committee on Antimicrobial Susceptibility Testing. 2015. Breakpoint tables for interpretation of MIC and zone diameters, version 4.0. ESCMID, Basel, Switzerland.

Fernandes MS, Fujimoto S, de Souza LP, Kabuki DY, da Silva MJ, Kuave AY. 2015. Dissemination of Enterococcus faecalis and Enterococcus faecium in a ricotta processing plant and evaluation of pathogenic and antibiotic resistance profiles. J Food Sci 80: M765-775.

Fridkin SK, Hageman J, McDougal LK, Mohammed J, Jarvis WR, Peri TM, Tenover FC; Vancomycin-Intermediate Staphylococcus aureus Epidemiology Study Group. 2003. Epidemiological and microbiological characterization of infections caused by Staphylococcus aureus with reduced susceptibility to vancomycin, United States, 1997-2001. Clin Infect Dis 36: 429-439.

Gales AC, Jones RN, Andrade SS, Pereira AS, Sader HS. 2005. In vitro activity of tigecycline, a new glycylcycline, tested against 1,326 clinical bacterial strains isolated from Latin America. Braz J Infect Dis 9: 348-356.

Gardete SC, Kim C, Hartmann BM, Mwangi M, Roux CM, Dunman PM, Chambers HF, Tomasz A. 2012. Genetic pathway in acquisition and loss of vancomycin resistance in a methicillin resistant Staphylococcus aureus (MRSA) strain of clonal type USA300. PLoS Pathog 8: e1002505.

Ge M, Chen Z, Onishi HR, Kohler J, Silver LL, Kerns R, Fukuzawa S, Thompson C, Kahne D. 1999. Vancomycin derivatives that inhibit peptidoglycan biosynthesis without binding D-Ala-D-Ala. Science 284: 507-511.

Gerhard U, Mackay JP, Maplestone RA, Williams DH. 1993. The role of the sugar and chlorine substituents in the dimerization of vancomycin antibiotics. J Am Chem Soc 115: 232-237.

Goldman RC, Baizman ER, Longley CB, Branstrom AA. 2000. Chlorobipehnyl-desleucyl-vancomycin inhibits the transglycosylation process required for peptidoglycan synthesis in bacteria in the absence of didpeptide binding. FEMS Microbiol Lett 183: 209-214.

Goldstein BP, Draghi FC, Sheehan DJ, Hogan P, Sahm DF. 2007. Bactericidal activity and resistance development profiling of dalbavancin. Antimicrob Agents Chemother 51: $1150-1154$.

Griffin JH, Linsell MS, Nodwell MB, Chen Q, Pace JL, Quast KI, Krause KM, Farrington L, Wu TX, Higgins DL, et al. 2003. Multivalent drug design: Synthesis and in vitro analysis of an array of vancomycin dimers. J Am Chem Soc 125: 6517-6531.

Hafer C, Lin Y, Kornblum J, Lowy FD, Uhlemann AC. 2012. Contribution of selected gene mutations to resistance in clinical isolates of vancomycin-intermediate Staphylococcus aureus. Antimicrob Agents Chemother 56: 5845-5851.

Hammes WP, Neuhaus FC. 1974. On the mechanism of action of vancomycin: Inhibition of peptidoglycan synthesis in Gaffkya homari. Antimicrob Agents Chemother 6: $722-728$.
Harris CM, Harris TM. 1982. Structure of the glycopeptides antibiotic vancomycin, Evidence for an asparagine residue in the peptide. J Am Chem Soc 104: 4293-4295

Higgins DL, Chang R, Debabov DV, Leung J, Wu T, Krause KM, Sandvik E, Hubbard JM, Kaniga K, Schmidt DE, et al. 2005. Telavancin, a multifunctional lipoglycopeptide, disrupts both cell wall synthesis and cell membrane integrity in methicillin-resistant Staphylococcus aureus. Antimicrob Agents Chemother 49: 1127-1134.

Hiramatsu K. 2001. Vancomycin-resistant Staphylococcus aureus: A new model of antibiotic resistance. Lancet Infect Dis 1: 147-155.

Howden BP, Stinear TP, Allen DL, Johnson PD, Ward PB, Davies JK. 2008. Genomic analysis reveals a point mutation in the two-component sensor gene graS that leads to intermediate vancomycin resistance in clinical Staphylococcus aureus. Antimicrob Agents Chemother 52: 37553762 .

Howden BP, Davies JK, Johnson PD, Stinear TP, Grayson ML. 2010. Reduced vancomycin susceptibility in Staphylococcus aureus, including vancomycin-intermediate and heterogeneous vancomycin-intermediate strains: Resistance mechanisms, laboratory detection, and clinical implications. Clin Microbio Rev 23: 99-139.

Howden BP, McEvoy CR, Allen DL, Chua K, Gao W, Harrison PF, Bell J, Coombs G, Bennett-Wood V, Porter JL, et al. 2011. Evolution of multidrug resistance during Staphylococcus aureus infection involves mutation of the essential two component regulator WalKR. PLoS Pathog 7: e1002359.

Howden BP, Peleg AY, Stinear TP. 2014. The evolution of vancomycin intermediate Staphylococcus aureus (VISA) and heterogenous-VISA. Infect Genet Evol 21: 575-582.

Jones RN, Sader HS, Flamm RK. 2013a. Update of dalbavancin spectrum and potency in the USA: Report from the SENTRY Antimicrobial Surveillance Program (2011). Diagn Microbiol Infect Dis 75: 304-307.

Jones RN, Sader HS, Mendes RE, Flamm RK. 2013b. Update on antimicrobial susceptibility trends among Streptococcus pneumoniae in the United States: Report of ceftaroline activity from the SENTRY antimicrobial surveillance program (1998-2011). Diagn Microbiol Infect Dis 75: $107-109$.

Judice JK, Pace JL. 2003. Semi-synthetic glycopeptide antibacterials. Biorg Med Chem Lett 13: 4165-4168.

Kahne D, Leimkuhler C, Lu W, Walsh C. 2005. Glycopeptide and lipoglycopeptide antibiotics. Chem Rev 105: 425448.

Karlowsky JA, Nichol K, Zhanel GG. 2015. Telavancin: Mechanisms of action, in vitro activity, and mechanisms of resistance. Clin Infect Dis 61: S58-S68.

Kato Y, Suzuki T, Ida T, Maebashi K. 2010. Genetic changes associated with glycopeptide resistance in Staphylococcus aureus: Predominance of amino acid substitutions in YvqF/VraSR. J Antimicrob Chemother 65: 37-45.

Kerns R, Dong SD, Fukuzawa S, Carbeck J, Kohler J, Silver L, Kahne D. 2002. The role of hydrophobic substituents in the biological activity of glycopeptide antibiotics. J Am Chem Soc 122: 12608-12609.

Kosowska-Shick K, Clark C, Pankush GA, McGhee P, Dewasse B, Beachel L, Appelbaum PC. 2009. Activity of telavancin against staphylococci and enterococci deter- 
D. Zeng et al.

mined by MIC and resistance selection studies. Antimicrob Agents Chemother 53: 4217-4224.

Krause KM, Benton BM, Higgins DL, Kaniga K, Renelli M, Humphrey PK. 2005. Telavancin possesses low potential for resistant mutant selection in serial passage studies of Staphylococcus aureus and enterococci. 15th European Congress of Clinical Microbiology and Infectious Diseases, Abstract P1577. Copenhagen, Denmark, April 2-5.

Krause KM, Blais J, Lewis SR, Lunde CS, Barrier SL, Friedland HD, Kitt MM, Benton BM. 2012. In vitro activity of telavancin and occurrence of vancomycin heteroresistance in isolates from patients enrolled in phase 3 clinical trials of hospital-acquired pneumonia. Diagn Microbiol Infect Dis 74: 429-431

Laohavaleeson S, Kuti JL, Nicolau DP. 2007. Telavancin: A novel lipoglycopeptide for serious Gram-positive infections. Expert Opin Investig Drugs 16: 347-57.

Leadbetter MR, Adams SM, Bazzini B, Fatheree PR, Karr DE, Krause KM, Lam BM, Linsell MS, Nodwell MB, Pace JL, et al. 2004. Hydrophobic vancomycin derivatives with improved ADME properties: Discovery of telavancin (TD-6424). J Antibiot (Tokyo) 57: 326-36.

Leclercq R, Derlot E, Duval J, Courvalin P. 1988. Plasmidmediated resistance to vancomycin and teicoplanin in Enterococcus faecium. N Engl J Med 319: 157-161.

Leimkuhler C, Chen L, Barrett D, Panzone G, Sun B, Falcone B, Oberthur M, Donadion S, Walker S, Kahne D. 2005 Differential inhibition of Staphylococcus aureus PBP2 by glycopeptide antibiotics. J Am Chem Soc 127: 32503251.

Leuthener KD, Yuen A, Mao Y, Rahbar A. 2015. Dalbavancin (BI-387) for the treatment of complicated skin and skin structure infection. Expert Rev Anti Infect Ther 13: 149159.

Levine DP. 2006. Vancomycin: A history. Clin Infect Dis 42: S5-S12.

Li L, Xu B. 2005. Multivalent vancomycins and related antibiotics against infectious diseases. Curr Pharmaceut Design 11: 3111-3124.

Linares J. 2001. The VISA/GISA problem: Therapeutic implications. Clin Microbiol Infect 7: 8-15.

Linsdell H, Toiron C, Bruix M, Rivas G, Menendez M. 1996. Dimerization of A82846B, vancomycin, and ristocetin Influence on antibiotic complexation with cell wall model peptides. J Antibiot 49: 181-193.

Loll PJ, Bevivino AE, Korty BD, Axelsen PH. 1997. Simultaneous recognition of a carboxylate-containing ligand and an intramolecular surrogate ligand in the crystal structure of an asymmetric vancomycin dimer. J Am Chem Soc 119: $1516-1522$.

Loll PJ, Miller R, Weeks CM, Axelsen PH. 1998. A ligandmediated dimerization mode for vancomycin. Chemist Biol 5: 293-298.

Loll PJ, Derhovanessian A, Shapovaloz MV, Kaplan J, Yang L, Axelsen PH. 2009. Vancomycin forms ligand-mediated supramolecular complexes. J Mol Biol 385: 200-211.

Lunde CS, Hartouni SR, Janc JW, Mammen M, Humphrey PP, Benton BM. 2009. Telavancin disrupts the functional integrity of the bacterial membrane through targeted interaction with the cell wall precursor lipid II. Antimicrob Agents Chemother 53: 3375-3383.
Mackay JP, Gerhard U, Beauregard DA, Maplestone RA, Williams DH. 1994a. Dissection of the contributions toward dimerization of glycopeptide antibiotics. $J$ Am Chem Soc 116: 4573-4580.

Mackay JP, Gerhard U, Beauregard DA, Westwell MS, Searle MS, Williams DH. 1994b. Glycopeptide antibiotic activity and the possible role of dimerization: A model for biological signaling. J Am Chem Soc 116: 4581-4590.

McCormick MH, McGuire JM, Pittenger GE, Pittenger RC, Stark WM. 1956. Vancomycin, a new antibiotic. I: Chemical and biologic properties. Antibiot Annu 3: 606-611.

Mitra S, Saeed U, Havlichek DH, Stein GE. 2015. Profile of oritavancin and its potential in the treatment of acute bacterial skin structure infections. Infect Drug Resist 8: 189-197.

Mouton JW, Jansz AR. 2001. The DUEL study: A multicenter in vitro evaluation of linezolid compared with other antibiotics in the Netherlands. Clin Microbiol Infect 7: 486-491.

Nagarajan R, 1994. Glycopeptide antibiotics. Drugs and the pharmaceutical sciences, Vol. 63. Marcel Dekker, New York.

Nebreda T, Oteo J, Aldea C, Garcia-Estebanez C, GasteluIturri J, Bautista V, Garcia-Cobos S, Campos J. 2007. Hospital dissemination of a clonal complex 17 vanB2containing Enterococcus faecium. J Antimicrob Chemother 59: 806-807.

Nicolau KC, Cho SY, Hughes R, Winssinger N, Smethurst C, Labischinski H, Endermann R. 2001a. Solid- and solution-phase synthesis of vancomycin and vancomycin analogues with activity against vancomycin-resistant bacteria. Chemistry 7: 3798-3823.

Nicolau KC, Hughes R, Cho SY, Winssinger N, Labischinski H, Endermann R. 2001b. Synthesis and biological evaluation of vancomycin dimers with potent activity against vancomycin-resistant bacteria: Target-accelerated combinatorial synthesis. Chemistry 7: 3824-3843.

Nieto M, Perkins HR. 1971. Physicochemical properties of vancomycin and iodovancomycin and their complexes with diacetyl-L-lysyl-D-alanyl-D-alanine. Biochem J 123: 773-787.

Nitani Y, Kikuchi T, Kakoi K, Hanamaki S, Fujisawa I, Aoki K. 2009. Crystal structures of the complexes between vancomycin and cell-wall precursor analogs. J Mol Biol 385: $1422-1432$

Pace JL, Krause K, Johnston D, Debabov D, Wu T, Farrington L, Lane C, Higgins D, Christensen D, Judice K, et al. 2003. In vitro activity of TD-6424 against Staphylococcus aureus. Antimicrob Agents Chemother 47: 3602-3604.

Perichon B, Courvalin P. 2009. VanA-type vancomycin-resistant Staphylococcus aureus. Antimicrob Agents Chemother 53: 4580-4587.

Perkins HR. 1969. Specificity of combination between mucopeptide precursors and vancomycin or ristocetin. Biochem J 111: 195-205.

Perkins HR, Nieto M. 1970. The preparation of iodinated vancomycin and its distribution in bacteria treated with the antibiotic. Biochem J 116: 83-92.

Peschel A, Vuong C, Otto M, Gotz F. 2000. The D-alanine residues of Staphylococcus aureus teichoic acids alter the 
susceptibility to vancomycin and the activity of autolytic enzymes. Antimicrob Agents Chemother 44: 2845-2847.

Pfeltz RF, Wilkinson BJ. 2004. The escalating challenge of vancomycin resistance in Staphylococcus aureus. Curr Drug Targets Infect Disord 4: 273-294.

Pootoolal J, Neu J, Wright GD. 2002. Glycopeptide antibiotic resistance. Annu Rev Pharmacol Toxicol 42: 381-408.

Rao J, Lahiri J, Isaacs L, Weis RW, Whitesides GM. 1998. A trivalent system from vancomycin-D-Ala-D-Ala with higher affinity than biotin-avidin. Science 280: 708-711.

Rao J, Yan L, Lahiri J, Whitesides GM, Weis RM, Warren HS 1999a. Binding of dimeric derivative of vancomycin to L-Lys-D-Ala-D-lactate in solution and at a surface. Chem Biol 6: 353-359.

Rao J, Yan L, Xu B, Whitesides GM. 1999b. Using surface plasmon resonance to study the binding of vancomycin and its dimer to self-assembled monolayers presenting $\mathrm{D}$ Ala-D-Ala. J Am Chem Soc 121: 2629-2630.

Rekharsky M, Hesek D, Lee M, Meroueh SO, Inoue Y, Mobashery S. 2006. Thermodynamics of interactions of vancomycin and synthetic surrogates of bacterial cell wall. J Am Chem Soc 128: 7736-7737.

Reynolds PE, Courvalin P. 2005. Vancomycin resistance in enterococci due to synthesis of precursors terminating in D-alanyl-D-serine. Antimicrob Agents Chemother 49: $21-25$.

Sahm DF, Benton BM, Cohen MA. 2006. Telavancin demonstrates low potential for in vitro selection of resistance among key target gram-positive species. Interscience Conference on Antimicrobial Agents and Chemotherapy. San Francisco, CA, September 27-30.

Samra Z, Ofer O, Shmuely H. 2005. Susceptibility of methicillin-resistant Staphylococcus aureus to vancomycin, teicoplanin, linezolid, pristinamycin and other antibiotics. Israel Med Assoc J 7: 148-150.

Schaefer M, Scheider TR, Scheldrick GM. 1996. Crystal structure of vancomycin. Structure 4: 1509-1515.

Sharman GJ, Try AC, Dancer RJ, Cho YR, Staroske T, Bardsley B, Maguire AJ, Cooper MA, O’Brie DP, Williams DH. 1997. The roles of dimerization and membrane anchoring in activity of glycopeptide antibiotics against vancomycin-resistant bacteria. J Am Chem Soc 119: 1204112047.

Shiozawa H, Zerela R, Bardsley B, Tuck KL, Williams DH. 2003. Noncovalent bond lengths and their cooperative shortening: Dimers of vancomycin group antibiotics in crystals and in solution. Helv Chim Acta 116: 1359-1370.

Shonekan D, Handwerger S, Mildvan D. 1997. Comparative in-vitro activities of RP59500 (quinupristin/dalfopristin), CL 329,998, CL 331,002, trovafloxacin, clinafloxacin, teicoplanin and vancomycin against Gram-positive bacteria. J Antimicrob Chemother 39: 405-409.

Sieradzki K, Tomasz A. 1997. Inhibition of cell wall turnover and autolysis by vancomycin in a highly vancomycinresistant mutant of Staphylococcus aureus. J Bacteriol 179: $2557-2566$.

Sieradzki K, Tomasz A. 2003. Alterations of cell wall structure and metabolism accompany reduced susceptibility to vancomycin in an isogenic series of clinical isolates of Staphylococcus aureus. J Bacteriol 185: 7103-7110.
Sieradzki K, Pinho MG, Tomasz A. 1999. Inactivated $p b p 4$ in highly glycopeptide-resistant laboratory mutants of Staphylococcus aureus. J Biol Chem 274: 18942-18946.

Sinha RK, Neuhaus F. 1968. Reversal of the vancomycin inhibition of peptidoglycan synthesis by cell walls. J Bacteriol 96: 374-382.

Smith JR, Roberts KD, Rybak MJ. 2015. Dalbavancin: A novel lipoglycopeptide antibiotic with extended activity against Gram-positive infections. Infect Dis Ther 4: 245258.

Song Y, Lunde CS, Benton BM, Wilkinson BJ. 2013. Studies on the mechanism of telavancin decreased susceptibility in a laboratory-derived mutant. Microb Drug Resist 19: $247-255$.

Stack DR, Letourneau DL, Mullen DL, Butler TF, Allen NE, Kline AD, Nicas TI, Thompson RC. 1998. Covalent glycopeptide dimers: Synthesis, physical characterization, and antibacterial activity. Intersci Conf Antimicrob Agents Chemother 37: 146.

Staroske T, Williams DH. 1998. Synthesis of covalent headto-tail dimers of vancomycin. Tetrahedron Lett 39: 49174920.

Sundram UN, Griffin JH, Nicas TJ. 1996. Novel vancomycin dimers with activity against vancomycin-resistant enterococci. J Am Chem Soc 118: 13107-13108.

Walsh TR, Howe RA. 2002. The prevalence and mechanisms of vancomycin resistance in Staphylococcus aureus. Annu Rev Microbiol 56: 657-675.

Walters M, Lonsway D, Rasheed K, Albrecht V, McAllister S, Limbago B, Kallen A. 2015. Investigation and control of vancomycin-resistant Staphylococcus aureus: A guide for health departments and infection control personnel. Centers for Disease Control and Prevention, Atlanta, GA.

Watanabe Y, Cui L, Katayama Y, Kozue K, Hiramatsu K. 2011. Impact of rpoB mutations on reduced vancomycin susceptibility in Staphylococcus aureus. J Clin Microbiol 49: $2680-2684$.

Wenzler E, Rodvold KA. 2015. Telavancin: The long and winding road from discovery to food and drug administration approvals and future directions. Clin Infect Dis 61: S38-S47.

Werner G, Klare I, Fleige C, Witte W. 2008. Increasing rates of vancomycin resistance among Enterococcus faecium isolated from German hospitals between 2004 and 2006 are due to wide clonal dissemination of vancomycinresistant enterococci and horizontal spread of vanA clusters. Int J Med Microbiol 298: 515-527.

Westwell MS, Gerhard U, Williams DH. 1995. Two conformers of the glycopeptide antibiotic teicoplanin with distinct ligand binding sites. J Antibiot 48: 1292-1298.

Westwell MS, Bardsley B, Dancer RJ, Try AC, Williams DH. 1996. Cooperativity in ligand binding expressed at a model cell membrane by the vancomycin group antibiotics Chem Commun 5: 589-590.

Williams DH. 1996. The glycopeptide story-How to kill the deadly "superbugs." Nat Prod Rep 13: 469.

Williams DH, Williamson MP, Butcher DW, Hammond SJ. 1983. Detailed binding sites of the antibiotics vancomycin and ristocetin A: Determination of intermolecular distances in antibiotic/substrate complexes by use of the time-dependent NOE. J Am Chem Soc 105: 1332-1339. 


\section{Zeng et al.}

Williams DH, Searle MS, Mackay JP, Gerhard U, Maplestone RA. 1993. Toward an estimation of binding constants in aqueous solution: Studies of associations of vancomycin group antibiotics. Proc Natl Acad Sci 90: 1172-1178.

Williams DH, Maguire AJ, Tsuzuki W, Westfall MS. 1998. An analysis of the origins of a cooperative binding energy of dimerization. Science 280: 711-714.

Williamson MP, Williams DH. 1981. Structure revision of the antibiotic vancomycin. Use of nuclear Overhauser effect difference spectroscopy. J Am Chem Soc 103: $6580-6585$.
Zhanel GG, Calic D, Schweizer F, Zelenitsky S, Adam H, Lagace-Wiens PR, Rubinstein E, Gin AS, Hoban DJ, Karlowsky JA. 2010. New lipoglycopeptides: A comparative review of dalbavancin, oritavancin and telavancin. Drugs 70: 859-886.

Zhu W, Murray PR, Huskins WC, Jernigan JA, McDonald LC, Clark NC, Anderson KF, McDougal LK, Hageman JC, Olsen-Rasmussen M, et al. 2010. Dissemination of an Enterococcus Inc18-like vanA plasmid associated with vancomycin-resistant Staphylococcus aureus. Antimicrob Agents Chemother 54: 4314-4320. 


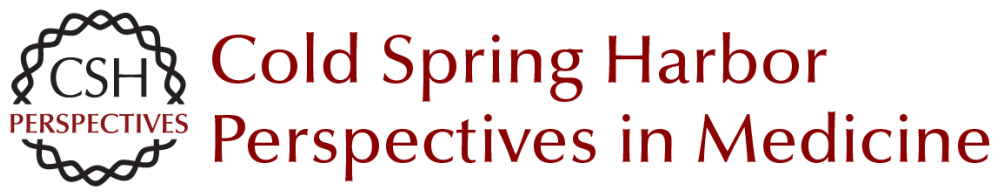

\title{
Approved Glycopeptide Antibacterial Drugs: Mechanism of Action and Resistance
}

\author{
Daina Zeng, Dmitri Debabov, Theresa L. Hartsell, Raul J. Cano, Stacy Adams, Jessica A. Schuyler, \\ Ronald McMillan and John L. Pace
}

Cold Spring Harb Perspect Med 2016; doi: 10.1101/cshperspect.a026989 originally published online September 23, 2016

\section{Subject Collection Antibiotics and Antibiotic Resistance}

Fosfomycin: Mechanism and Resistance Lynn L. Silver

Pleuromutilins: Potent Drugs for Resistant Bugs

--Mode of Action and Resistance Susanne Paukner and Rosemarie Riedl

Appropriate Targets for Antibacterial Drugs Lynn L. Silver

Lincosamides, Streptogramins, Phenicols, and Pleuromutilins: Mode of Action and Mechanisms of Resistance

Stefan Schwarz, Jianzhong Shen, Kristina Kadlec, et al.

Resistance to Macrolide Antibiotics in Public Health Pathogens

Corey Fyfe, Trudy H. Grossman, Kathy Kerstein, et al.

Bacterial Protein Synthesis as a Target for

Antibiotic Inhibition

Stefan Arenz and Daniel N. Wilson

Antibacterial Antifolates: From Development through Resistance to the Next Generation Alexavier Estrada, Dennis L. Wright and Amy C. Anderson

Antibacterial Drug Discovery Targeting the Lipopolysaccharide Biosynthetic Enzyme LpxC Alice L. Erwin
The Whys and Wherefores of Antibiotic

Resistance

Cameron R. Strachan and Julian Davies

$\beta$-Lactamases: A Focus on Current Challenges Robert A. Bonomo

Approved Glycopeptide Antibacterial Drugs: Mechanism of Action and Resistance Daina Zeng, Dmitri Debabov, Theresa L. Hartsell, et al.

Mechanism of Action and Resistance to Daptomycin in Staphylococcus aureus and Enterococci William R. Miller, Arnold S. Bayer and Cesar A. Arias

Polymyxin: Alternative Mechanisms of Action and Resistance

Michael J. Trimble, Patrik Mlynárcik, Milan Kolár, et al.

Topoisomerase Inhibitors: Fluoroquinolone Mechanisms of Action and Resistance David C. Hooper and George A. Jacoby

$\beta$-Lactams and $\beta$-Lactamase Inhibitors: An Overview Karen Bush and Patricia A. Bradford

Rifamycins, Alone and in Combination David M. Rothstein

For additional articles in this collection, see http://perspectivesinmedicine.cshlp.org/cgi/collection/ 